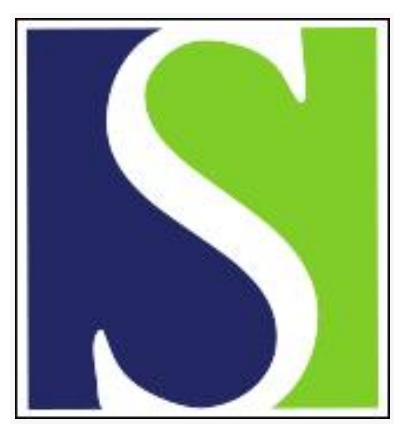

Scand J Work Environ Health 1997;23(5):321-324

https://doi.org/10.5271/sjweh.227

Issue date: Oct 1997

\title{
New vistal in occupational health
}

by Westerholm $\mathrm{P}$

This article in PubMed: www.ncbi.nlm.nih.gov/pubmed/9403461

\section{(c) (1)}


Scand J Work Environ Health 1997;23:321-4

\section{New vistas in occupational health}

This issue of the Scandinavian Journal of Work, Environment \& Health contains a commendable review on national development in occupational health and safety by Edward A Emmett (1). It is based on observations of central trends and experiences in Australia. The review describes developments relevant to occupational health and raises a whole range of issues that is clearly pertinent in a global perspective. The paper carries a distinct Australian flavor, giving ample reference to legislation and regulations adopted in the occupational health field in Australia. Still, most of the observations are strikingly relevant and valid also in other parts of the world. For northern European readers in particular — being myself one of them - it is easy to follow the direction of change and the description of pitfalls encountered in route.

The volume constraints on an editorial column imposes limitations on commenting on all the complex issues involved in these changing horizons of occupational health. Therefore, a selection of a few points for discussion will have to suffice.

The historical perspective given by Emmett - in the form of a description of the phase referred to as the "classical" — is valuable. In Australia the duration of this phase was — in broad terms - from the 1890 s to 1980 . For an understanding of what is happening in the present, a scrutiny of the past is often necessary, and it often provides cues for the future. Emmett describes the strategies of regulations, specific preventive interventions, statistics, information, teaching, and research as the core elements of a comprehensive approach implemented on the national level during the period referred to as "moderntraditional", which extended roughly over the 1980s. At the end of this phase, the whole agenda came under close scrutiny in the face of the tightening economy and the increasing general awareness of a need to rethink the priorities, objectives, and values of good occupational health care. It was realized that occupational health was not just there, free for the taking. This realization gave birth to the present, ongoing stage referred to by Emmett as the "occupational health and safety performance phase". The forces propelling this transition were primarily the sharpening competition among enterprises in the global marketplace, the disaffection with some major economic blunders by the political leadership at the time, an increasing reliance on market forces in bringing about desired changes in the labor market and enterprises, the decentralization of decision making, and, in some quarters, enthusiasm for general deregulation. The bottom line of all these trends added up to a new political climate that carried implications for occupational health and safety, starting in the early 1990s. Emmett makes a well argued point in referring to this change as a new paradigm.

These changes raise, by implication, issues of fundamental importance, such as the role of state agencies in promulgating new regulations and standards and inspecting their implementation. They also bring into focus, once again, a new awareness of the importance of actions at the enterprise level. The difficulties of regulatory agencies are simply enormous in keeping an even pace with developments in a dynamically evolving world with the corollary of necessary adaptations on national and enterprise levels with a view to an adequate output of regulations and guidance for implementation. All this change occurs in a context of sharpening competition and specialization. The market rules and cash is king.

We have seen the same trends in Europe. I would add the changing panorama of workplace hazards to the aspects highlighted by Emmett. We see fewer chemical and physical hazards. We pay, at the same time, more attention to psychological, social, and cultural factors or health determinants operating at work. There is less occupational disease - setting aside, for the moment, the legal connotations of this term — and more illness and sickness. 
Disease is a term commonly used for states of health aberration in which the diagnosis is primarily based on diagnostic findings and observations, with or without pathologic, pathophysiological or biochemical correlates. Illness is a category of health aberration in which the diagnosis relies basically on symptoms and sensations as perceived by the subject or patient. Sickness denotes the subjects' behavior in relation to the social security or insurance system. Absenteeism for health reasons is, for instance, and following this terminology, a phenomenon of sickness.

When this shift of emphasis from occupational disease towards occupational illness and sickness is taken into account it is a painful but sobering thought that we are still unable to explain convincingly such illness manifestations as repetitive strain injury and fibromyalgia in the neck and shoulder region in terms of the classical biomedical disease model. One of the essential stumbling blocks seems actually to be our lack of a truly operational definition of "health". Use of the well-known definition of the World Health Organization is not very rewarding. The qualification of this concept to "occupational health" may sometimes be useful, but it does not take us much further.

The concept of quality in occupational health and safety is nowadays explored and discussed extensively and for good reasons. The term quality has found its way into the field of occupational health and safety via the practices of industry. In some countries it has been thrust on occupational health professionals by government agencies. In others its pursuit has been chosen as a strategy for competition and, ultimately, survival in market-based health care systems. We are learning to distinguish between the different meanings given to it by health professionals, health care managers and enterprises, including enterprise management and employees. Quality can be assured, even to a formal status of certification, but these processes have, up to now, only just begun. There are pressures for change, though, and I believe it safe to predict that, in the coming decade, we will see significant development in approaches, methods and techniques for establishing quality systems in occupational health and safety structures and procedures. Many occupational health services will perceive a need to develop quality assurance as they implement quality management cycles followed by, as the ultimate goal, total quality management (TQM).

There are many reasons for the difficulties in initiating quality processes in occupational safety and health services. The most important are (i) the fact that poor quality is not immediately obvious to clients and consumers and routine (standard) measures have not yet been developed and (ii) clients and consumers of health services have, to a large extent, not had the expertise and power to assess and demand quality.

These obstacles will have to be overcome, and I belong myself to those preferring to have confidence in our professional coping capacity in this regard. The most important major inhibiting factor to quality development probably resides in ourselves, our own resistance to change. We see a good deal of skepticism among key players in the professional cadres. The objections raised range from reservations concerning the resources and time required for quality work to the risks of being swamped with paperwork produced by ourselves and bringing only doubtful benefits to the service provided. There are also the problems fraught with achieving everyone's commitment to the tasks at hand. Staff already has to cope with many tasks deriving from the reforming and re-orienting of services, and the question "When are we supposed to do our real job?" has to be given a convincing answer. So, there is still some way to go.

It is nevertheless important to keep in mind that the ultimate aim of quality work is continuous quality improvement and that quality management is a responsibility shared by management and staff. This aim certainly applies in occupational safety and health.

In parallel with the developments in the global marketplace and the changes in production technology with their significant impact on work conditions, both in industry and in the service sector, changes are taking place in the health care systems of many countries. A general search is in progress for better 
health care structuring. In most countries it is becoming increasingly difficult, and perhaps not even meaningful, to draw sharp distinctions between the tasks of public health and occupational health systems. The core question confronting occupational health and safety services is, as it has always been, "Who is the customer?" It is relatively easy to point at benefits and beneficial outputs of services for individual members of enterprise staff. The task is considerably more challenging when it comes to benefits on a collective level, such as for an enterprise or group of employees or a production system. The benefits produced by such services on the society level appear to be still more remote. To demonstrate their basis of evidence is certainly a daunting task. I am, however, convinced that one of the greatest challenges for occupational health and safety professionals is, to put it very plainly, to demonstrate convincingly the value of the services they provide. This applies at all three levels, that of society, the enterprise, and the individual.

When looking at health service organizations in various countries - and we must remember that occupational health systems do have health as an ultimate objective - we can discern some interesting trends. In countries with public funding for health services the trend is largely to introduce market solutions and competition, with or without relaxation of public funding (eg, in the United Kingdom and Sweden). In market-based systems those seeking change look for more government intervention (eg, in the United States). In countries with a high degree of public funding for health care, insurance-based solutions are sought (eg, in The Netherlands). In countries where funding of health care is insurance based, coordinated and comprehensive systems are looked for (eg, in the United States).

In describing the course of development in the field of occupational health in Australia, Emmett refers to the ongoing process in Europe by observing some parallels. Yes, there are indeed significant analogies. The European stage may actually be described as a process of experimentation during the period starting in the early 1960 s to the late 1980 s, in search of regulatory instruments relevant to occupational health and safety matters in a modern context. It has included the steps of the first social action program of 1974, the so-called "new approach" adopted in 1985, the single act of the European Union (EU) on occupational safety of 1987 that led to the EU framework directive of 1989 (391/89). The framework directive marks an entrance into a new era of regulatory thinking in occupational health. The focus is set on the enterprise level. It has been devised to serve as a basis for the twin objectives of providing a comprehensive basis for regulatory work and also converging practices in the European Union. It is, in this context, also appropriate to remember the social clause agreement of December 1991 in Maastricht as a component part of the European regulatory system.

In contemplating this development, so deeply embedded in the economical, technological and political processes, and considering its occupational health implications, it is obvious that it has taken us all into uncharted waters. We are all amateurs, doing our best to adapt occupational health practices to an entirely new context. The horizon of workplace hazards has simply changed, and we also see them in a different light today. The situation is difficult and we are practically bound to commit mistakes, in the blissful hope that they might not turn out to be too serious.

Learning-by-doing is not the most efficient way of advancing, but what is our alternative? In the world of practical affairs decisions have to be made, almost always under conditions of imperfect information. We colild, however, learn more if we were to use evaluative approaches more consistently in framing regulatory or research policies or in organizing occupational health programs. Starting by asking sharp questions on important issues such as objectives, processes and envisaged outcomes at the outset and following them up with implementation. Evaluations are necessary if we seriously intend to transform our societies into learning organizations. At the end of the day, we simply have to accept that there are inherent limitations to our approaches. This statement applies to researchers, practitioners and regulators in the field of occupational health. Politics, certainly, has its limits. 
A quality feature of Emmett's review is the guided tour taking the reader through the stages of development in Australia, commenting on flaws and experiences at each stage and highlighting such important subject matters as regulatory reforms, pursuit of quality, research and training aspects, and stakeholder and consumer participation. The introduced subject matter is of considerable scope and therefore makes for strict condensation of text and leaves little room for analysis and explanations in depth. There is, however, much to be read also between the lines for the attentive reader in this straightforward narrative.

Emmett has brought up a subject with many implications for occupational health practice and for research. There are many possible ramifications to take up in further contributions to the debate which he has started. It is, for obvious reasons, not feasible to capture all aspects to the full satisfaction of everyone in one paper. The Scandinavian Journal of Work, Environment \& Health fully recognizes the importance of the themes thus brought up and welcomes contributions and discussion in the same vein from its readers. These can be drafted as "Commentaries" or "Letters to the Editor" on the intricacies of the issues involved. This suggestion applies to particular issues related to the strategies and roles of occupational health professionals - including the challenges to professional ethics - facing customers and markets in a changing world. I am not alone in sensing an uneasy feeling that we are, as occupational health professionals, heading for an existential crisis. Some of us are, in fact, already deeply immersed. This should not to be taken to be an apocalyptic prediction. Only that we are well advised to take a close look at our own roles, priorities, and practices and to reappraise what we are doing in facing the challenges of both our own age and what may lie ahead. For such purposes Emmett has provided an excellent point of departure.

\section{Reference}

1. Emmett EA. National development of occupational health and safety in Australia. Scand J Work Environ Health 1997 ; $5: 325-33$.

\section{Professor Peter Westerholm \\ Department of Occupational Health \\ National Institute of Working Life \\ 17184 Solna Sweden \\ [E-mail: pwholm@niwl.se]}

Key terms occupational health trends, occupational health development 